CARTA AL EDITOR

\section{ENFERMEDAD PULMONAR POR Mycobacterium chelonae EN UNA PACIENTE INMUNOCOMPETENTE TRATADA EXITOSAMENTE CON LINEZOLID}

\author{
LUNG DISEASE BY Mycobacterium chelonae \\ IN AN IMMUNOCOMPETENT PATIENT \\ SUCCESSFULLY TREATED WITH LINEZOLID
}

\author{
Samuel Pecho-Silva (101,2,a , Ana Claudia Navarro-Solsol (1)3,b \\ 1 Hospital Nacional Edgardo Rebagliati Martins, Lima, Perú. \\ 2 Universidad Científica del Sur, Lima, Perú. \\ 3 Universidad Nacional de Ucayali, Pucallpa, Perú. \\ a Médico especialista en Neumología; ${ }^{\mathrm{b}}$ médica cirujana.
}

Sr. Editor: Hemos leído con mucho interés el primer reporte sobre un paciente con Mycobacterium intracellulare en Perú ${ }^{(1)}$ y queremos contribuir indicando que el tratamiento de las micobacterias no tuberculosas (MNT) es posible cuando se logra una identificación oportuna y se administra un tratamiento de acuerdo con los consensos internacionales ${ }^{(2,3)}$.

Las MNT son especies del género Mycobacterium, pero no forman parte del complejo Mycobacterium tuberculosis o leprae, por lo que su tratamiento, identificación y métodos para determinar la sensibilidad a los medicamentos son distintos ${ }^{(1-3)}$. Al igual que los autores del reporte, hemos identificado el primer caso peruano de enfermedad pulmonar por Mycobacterium chelonae en una paciente inmunocompetente que fue tratada exitosamente con linezolid en el Perú.

En enero del 2014 se recibió en el consultorio externo del Hospital Nacional Edgardo Rebagliati Martins a una mujer de 67 años, activa, lúcida y estable, que respiraba aire ambiental con una saturación de oxígeno de 94\%. Manifestó que tenía tos, expectoración, pérdida de peso y episodios de fiebre intermitente, además de hipoacusia causada por medicamentos.

La paciente tenía antecedente de tuberculosis pulmonar, por lo que en octubre de 1999 inició tratamiento por seis meses con isoniacida, rifampicina, etambutol y pirazinamida, y se le dio el alta. La paciente también mencionó que, por indicación del Programa de Control de la Tuberculosis (PCT), había dejado de tomar la medicación antituberculosa durante dos meses, y que no tenía diagnóstico de ninguna enfermedad concomitante crónica, ni inmunosupresora.

Citar como: Pecho-Silva S, Navarro-Solsol AC. Enfermedad pulmonar por Mycobacterium chelonae en una paciente inmunocompetente tratada exitosamente con linezolid. Rev Peru Med Exp Salud Publica. 2020;37(4). doi: https://doi. org/10.17843/rpmesp.2020.374.6186.

Correspondencia: Samuel Pecho-Silva; Jirón Moore 228, dpto. 201, Magdalena del Mar, Lima, Perú; samuelpechosilva@gmail.com

Recibido: 19/07/2020 Aprobado: 28/08/2020 En línea: 05/11/2020
Desde junio del 2001 hasta noviembre del 2013, debido a la persistencia de síntomas respiratorios, la paciente fue tratada por el PCT con medicamentos en diferentes esquemas y combinaciones: isoniacida, rifampicina, etambutol, pirazinamida, estreptomicina, ciprofloxacino, kanamicina, etionamida, amoxicilina/ácido clavulánico, capreomicina, cicloserina, ácido paraaminosalicílico, amikacina, moxifloxacino, claritromicina, clotrimoxazol, doxiciclina, cefoxitina, azitromicina y levofloxacino. A pesar de recibir estos medicamentos, la paciente no se curó, ya que sus cultivos de esputo se mantuvieron positivos. En octubre del 2013 fue considerada por el PCT como un «fracaso sin opción quirúrgica».

La presencia de Mycobacterium chelonae se había confirmado en diferentes fechas y laboratorios; en junio del 2004, diciembre del 2006 y enero del 2014 en el Instituto Nacional de Salud del Perú; en noviembre del 2004 en el Instituto Nacional de Salud de Chile; en marzo del 2004 en el laboratorio del Hospital Cayetano Heredia; en enero del 2014 y mayo del 2014 en el laboratorio del Hospital Nacional Edgardo Rebagliati Martins. Desde el 2004, la paciente cumplía con todos los criterios diagnósticos de enfermedad pulmonar por Mycobacterium chelonae propuestos por The American Thoracic Society, European Respiratory Society, European Society of Clinical Microbiology and Infectious Diseases y Infectious Diseases Society of America (ATS/ERS/ESCMID/IDSA) ${ }^{(1,2)}$.

En mayo del 2014, la paciente inició un tratamiento combinado (según las recomendaciones de ATS/ERS/ESCMID/ IDSA) que consistía en imipenem $1 \mathrm{~g}$ vía endovenosa (EV) dos veces al día (b.i.d.), linezolid 600 mg EV b.i.d., amikacina $500 \mathrm{mg}$ nebulizada b.i.d., moxifloxacino $400 \mathrm{mg}$ vía oral (VO) una vez al día (q.d.) y claritromicina $1 \mathrm{~g}$ VO q.d. La paciente fue hospitalizada inicialmente para que se le hiciera un control de posibles reacciones adversas ${ }^{(4-6)}$. En junio del 2014 se le colocó un catéter venoso central tipo Port-A-Cath para la administración de medicación EV. En septiembre del 2014, se suspendió el imipenem (luego de cuatro meses de tratamiento), se cambió la administración del linezolid a 600 mg VO q.d, y se administraron junto con claritromicina y moxifloxacino que mantenían las dosis iniciales. La paciente recibió el alta hospitalaria en septiembre del 2014. El primer cultivo negativo se obtuvo en junio de ese mismo año (un mes después del nuevo tratamiento). Durante los doce meses siguientes se le realizaron cultivos mensuales, cuyos resultados fueron negativos. El tratamiento tuvo una duración de trece meses; se le dio el alta farmacológica en junio del 2015.

Entre las reacciones adversas se registró disfonía asociada a la amikacina nebulizada, por lo que se suspendió su uso luego de tres meses de tratamiento. También presentó neuropatía periférica leve en miembros inferiores asociada al linezolid, lo que se confirmó por electromiografía. Esta neuropatía se controló con amitriptilina, y no fue necesario suspender el medicamento. En el 2018, tres años después del alta farmacológica, la paciente cumplió con los criterios de insuficiencia respiratoria crónica, secundaria a las lesiones pulmonares, por lo que recibió tratamiento domiciliario con oxígeno, entre uno a dos litros por minuto (Figura 1). 


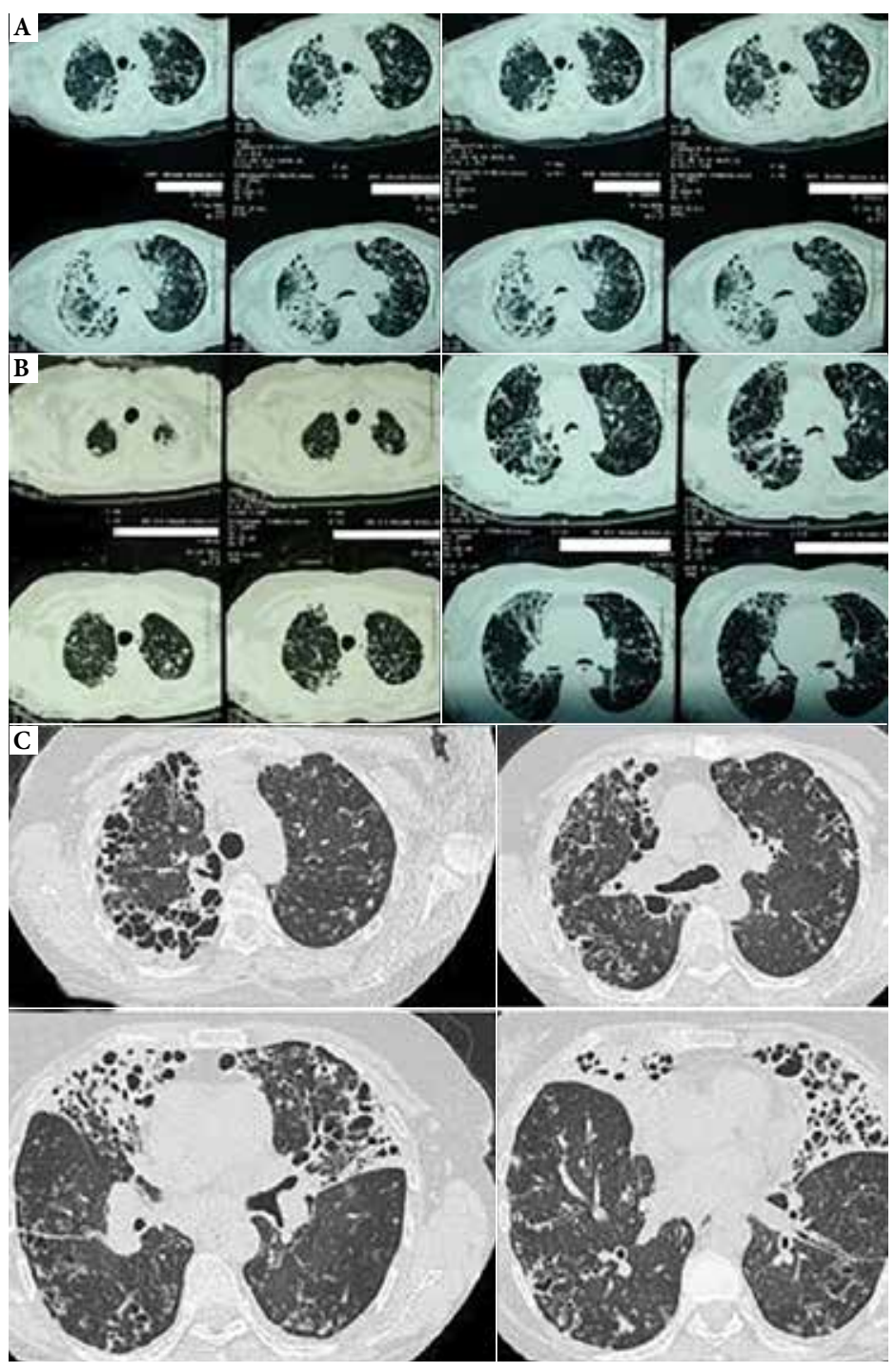

Figura 1. Imágenes tomográficas. A) En enero del 2014, antes del nuevo tratamiento se observan lesiones inflamatorias agudas bilaterales. B) En julio del 2014, luego de un mes del nuevo tratamiento, se observa mejoría del proceso inflamatorio agudo. C) En febrero del 2018, se observan lesiones fibróticas secuelares bilaterales extensas.

Entre el 2015 y 2019, se le realizaron múltiples exámenes de esputo, sin encontrar MNT. En septiembre del 2019, la paciente falleció en su casa, por complicaciones secundarias a las lesiones pulmonares bilaterales.

Se concluye que, de haber recibido un tratamiento adecuado y precoz acorde a los consensos del ATS/ERS/ESCMID/IDSA, se hubiera podido evitar la extensión de las lesiones pulmonares y reducir el sufrimiento de la paciente a consecuencia de los doce años de medicación inadecuada. Se sugiere que sean neumólogos especializados en MNT quienes se encarguen del manejo de estas, ya que su tratamiento es distinto del tratamiento de la Mycobacterium tuberculosis.

Criterios éticos: Se obtuvo el consentimiento informado de la paciente. El permiso institucional del Hospital Nacional Edgardo Rebagliati Martins fue otorgado por la jefatura del servicio.
Contribuciones de los autores: SPS y ACNS han participado en todo el proceso de concepción, diseño, redacción y aprobación final del artículo.

Financiamiento: Autofinanciado.

Conflictos de interés: No existen conflictos que declarar.

\section{REFERENCIAS BIBLIOGRÁFICAS}

1. Accinelli RA, Camposano A. Enfermedad pulmonar por Mycobacterium intracellulare en una paciente inmunocompetente: reporte de un caso en el Perú. Rev Peru Med Exp Salud Publica. 2020;37(2):361-6. doi: 10.17843/ rpmesp.2020.372.4632.

2. Haworth CS, Banks J, Capstick T, Fisher AJ, Gorsuch T, Laurenson IF, et al. British Thoracic Society Guideline for the management of nontuberculous mycobacterial pulmonary disease (NTMPD). BMJ Open Resp Res. 2017;4:e000242. doi: 10.1136/bmjresp-2017-000242. 
3. Griffith DE. Treatment of Mycobacterium avium Complex (MAC). Semin Respir Crit Care Med. 2018;39(3):351-361. doi: 10.1055/s-0038-1660472.

4. van Ingen J, van der Laan T, Dekhuijzen R, Boeree M, van Soolingen D. In vitro drug susceptibility of 2275 clinical non-tuberculous Mycobacterium isolates of 49 species in The Netherlands. Int J Antimicrob Agents. 2010;35(2):169-173. doi: 10.1016/j.jiantimicag.2009.09.023.

5. Daley CL, Iaccarino JM, Lange C, Cambau E, Wallace RJ, Andrejak C, et al. Treatment of Nontuberculous Mycobacterial Pulmonary Disease: An
Official ATS/ERS/ESCMID/IDSA Clinical Practice Guideline: Executive Summary. Clin Infect Dis. 2020;71(4):e1-e36. doi: 10.1093/cid/ciaa241.

6. Wallace RJ Jr, Dukart G, Brown-Elliott BA, Griffith DE, Scerpella EG, Marshall B. Clinical experience in 52 patients with tigecycline-containing regimens for salvage treatment of Mycobacterium abscessus and Mycobacterium chelonae infections. J Antimicrob Chemother. 2014;69(7):1945-1953. doi: 10.1093/jac/dku062. 